\title{
TEAM LEADERSHIP AS A DIRECTION OF TRAINING PROFESSIONAL PSYCHOLOGISTS
}

Tahir Y. Bazarov

Lomonosov Moscow State University, Russia

E-mail: thbazarov@mail.ru

Vladimir S. Karapetyan Armenian State Pedagogical University after Kh. Abovyan, Armenia

E-mail: vskarapetyan@mail.ru

Srbui R. Gevorgyan

Armenian State Pedagogical University after Kh. Abovyan, Armenia

E-mail: gevorgyan_26@mail.ru

\begin{abstract}
Nowadays, nearly all the specialists have to operate in unpredictable situations. The group leader has to be capable to realize effective group performance. As it has been already mentioned (Bazarov, Shevchenko, 2013), "The post-crisis era executive leader should possess such important traits as self adjustment; common sense in combination with intuition, emotions, and imagination; and the readiness to make choices in fifty-fifty situations. The most general definition of "self-adjustment" is the building of functional interconnections between (1) a subject's actions and state and (2) the actions and state of the surrounding setting. Building such interconnections allows for introducing relevant and purposeful changes in the subject's actions, depending on the feedback from the previous step. In other words, this is an algorithm of changes based on feedback. ". So in our opinion, a framework is needed that integrates existing team leadership research and the full range of ways in which leadership can manifest itself within the team.

1. Four types of organization of joint activities predict the facet of the organizational culture

2. Four types of organizational culture give rise to four types of working groups

3. Four types of organizational culture assume four types of leadership as well

4. The essential difference between these cultures is determined by those forms of organization of joint activities which underlies them.
\end{abstract}

Key words: organizational culture, joint activity, type of working group, team leadership.

\section{Introduction}

Students' productive and educational experience is not only a transfer of knowledge on the future profession, but also a special form of socialization of the new generation of specialists. In this respect, it is essential to prepare psychologists for a joint creative activity in today's organizational reality. Here it is necessary to pay attention to the formation of the qualities of a "team player" in 
graduates. Different organizational cultures distinguish members of one team from another. People create them as mechanisms of social experience that help to live in their environment and preserve the integrity of the community in collaboration with other communities.

According to Cameron and Quinn (1999) culture defines the core values, assumptions, interpretations and approaches that characterize an organization. Most of organization scholars and observers recognize that organizational culture has a powerful effect on the performance and long-term effectiveness of organization. Empirical research has produced an impressive area of findings demonstrating the importance of culture to enhancing organizational performances.

The following basic historical types of organizational cultures that give rise to four types of working groups and four types of leadership in a team can be distinguished. The essential difference between these cultures is determined by those forms of organization of joint activities which underlie them (Table 1).

\section{Table 1. Types of organizational cultures.}

\begin{tabular}{cccc}
\hline $\begin{array}{c}\text { Type of organizational } \\
\text { culture }\end{array}$ & Type of joint activity & Type of working group & Type of a leader \\
\hline Bureaucratic & Co-Operative & Combine & Commander \\
Organic & Co-Interactive & Clique & Hero-Visionary \\
Entrepreneurial & Co-Individual & Enterprise & Coordinator \\
Participatory & Co-Creative & Team & Superleader \\
\hline
\end{tabular}

\section{Theoretical Framework}

\section{“Combine” Working Group Type}

Co-operative type of activity is characterized by time-distribution and consistent order of participation of each employee in the work. Consistency assumes that at the beginning the first employee is engaged in work, then the second, the third and so on. The features of the activity of each work participant are instructed with the specificity of transforming the means into results. For example, in the manufacturing of boards, one first cuts trees, then another one takes them to the factory, next one separates the trunk from the branches, later, another one measures the trunk and counts the quantity and the size of the boards he can get and what the chart of sawing will be, only after this the trunk is taken to sawing. A typical example of co-operative type of interaction is the conveyor, when the product is automatically transferred to the next participant and becomes an object of labor (Human Resource Management, 2006).

"Combine" working group type is characterized as a formalized and structured workplace. What people do is supervising the work process. Effective leaders are good coordinators and organizers. It is important to maintain smooth work progress. Long-term concerns of the team are to provide stability, predictability and profitability. People are united by formal rules and official policy.

There are some basic tasks and skills for members in a group such as:

1. The worker should identify ambition and needs of potential group members as perceived by members, worker and organization.

2. The worker has to obtain organizational uphold for and affirmation of the group.

3. The worker should select the group type, structure, operation and size that will be arrogate for attaining the aims of the group.

4. The worker should reach out to and recruit potential group members.

5. The worker should obtain consent from potential members and relevant others as required by ethical guidelines and organizational conditions ( Standards for Social Work Practice with Groups, 2013). 
OF PSYCHOLOGY IN THE $21^{\text {st }}$ CENTURY Vol. 9, No. 1, 2015

Characteristics of a "Commander"

Mode of impact: power

Specification of the method: enforcement

Form of communication: command

Form of stating the problem: a precise description of the form of the result and verifying points. Objectives are linked to sanctions.

Perception of the worker: a tool for the implementation/realization of tasks who is lazy by nature and needs to be controlled.

Valuable qualities: diligence and commitment

Criteria of leader's efficiency: indisputable fulfillment of the task by workers. Instructor's word is a law. When workers are afraid it means they respect.

$$
\text { “Clique” Working Group Type }
$$

Co-interactive type is characterized by the obligatory participation of everyone in a common task, labor intensity of the employees is approximately the same, features of their activities are determined by the work instructors and, as a rule, they are less changeable. The effectiveness of the joint activity is equally dependent on the work of each employee. An illustration of such an option of organizing joint activity may serve the joint replacement of loads (Human Resource Management, 2006).

"Clique" working group type is characterized as a friendly workplace where people have a lot in common and rely on each other. It is like a big family. Leaders think as educators, and, perhaps, even as parents. The team keeps together, thanks to dedication and traditions. It puts an emphasis on the long-term benefit from the enhancement of an individual and gives a high degree of importance to the team unity and moral environment. Success is certain, in case of a healthy inner environment and care of people.

Characteristics of a "Commander"

Mode of impact: emotional and motivational impact.

Specification of the method: awakening of emotions, energizing, working with the emotional state (including stress relieving, creating feelings of confidence) and individual motivation of a worker (with its features).

Form of communication: personal example, agitation, reliable conversation.

Form of stating the problem: an emphasis on the emotional side of the matter and relationships, formulation in the form of a request, a draft.

Perception of the employee: a living person with his/her weaknesses and moods, who is in need of care and attention.

Valuable qualities: dedication and reliability.

Criteria of leader's efficiency: love and dedication of workers.

According to Colonel, (2005) the commander is a person who points where he can best influence the progress of the certain campaign, the person who makes timely decisions appropriate to his level of command. As a matter of fact, dilemma stems from the demands on his time from the functions that all commanders are required to perform: firstly, leadership and, of course, command. Leadership tends to be defined in terms of the qualities a leader ought to possess in order to motivate and inspire, his presence, his own personality and character. It is widely known that command is more of a management function, which requires a systems approach. The balance between the leadership and command functions will vary according to the phase of an operation or campaign, the level, or size of the command being exercised, national doctrine and the means available for information flow. At the lower tactical levels of command, and here, we generally accept a divisional level as the top end, commanders are able, and in many cases required, to have 
direct involvement in the battle. Indeed, at the very lowest levels, and here, I mean, the company and below, the primary function is to lead. That is to say, commanders can exert influence through their personal example, inspiring those around them, and where their personal intervention at the precise moment in time and space may be bound.

\section{“Concern” Working Group Type}

Horses harnessed to the chariot run faster than one at a time not for they cut through the air easily with joint efforts, but for they are incited by the competition and rivalry with each other.

Plutarchos, an ancient Greek historian $(46,127)$

Co-individual type is distinguished for the minimized interaction between the work participants. Each of the workers does his amount of work and the specifics of the activity is defined by individual characteristics and professional positions of each employee. Each of the workers presents the results of the work done in a specified manner and in a particular place. Private direct interaction may be practically missing and can be realized through modern means of communication, i.e. phone, computer networks, etc.). Only the subject of the work, which is processed in a specific way by each worker, does unite different workers. As examples of this type of activity may serve an individual transport of loads or an independent analysis of different aspects of the same phenomenon by different specialists. (Human Resource Management, 2006).

"Concern" working group type is characterized by the orientation on the accomplishment of the task. An emphasis is put on the desire to win. Team leaders appear to be solid managers and severe/tough rivals. Success is determined by penetrations into markets and an increase of market share. People are characterized with their determination and competence with one another. They are characterized by a high initiative, patience, orientation on the result and individual achievement. Such specialists give priority to own goals and values, tend to develop their own ways of achieving goals and are able to operate/act effectively in cases of intraorganizational competition. This group type may have trouble organizing overall activities between different specialists who know very well their own business, but are less focused on understanding the characteristics of their colleagues, who are more concentrated on problems of their own activities than on the problems of the team as a whole. As Badke-Schaub, Neumann, Lauche and Mohammed, (2007) suggested most early experiment done on mental models concentrates on the investigation of individual mental models, and it took more than 10 years until the concept of mental models was introduced to team settings. Shared or team mental models (TMM) are characterized as knowledge form - belief structures that are shared by the members of a team, which enable them to form correct clarifications and expectations about the task, and to coordinate their doing and adjust their behavior to the demands of the task and other team members. The term team mental model is not meant to only refer to multiple levels or sets of shared knowledge or just to an aggregate of the individual mental models, but also to a synergistic functional aggregation of the teams mental functioning representing similarity, overlap, and complementarity. As team mental models delineate both of individual mental models and how they are shared or distributed within a team, this concept seems very suitable to investigate how complex obstacles are solved inside of groups. Design problems can be defined as specific kinds of complex problem-resolution. As a matter of fact, using team mental model research to examine design problems might help to understand how the solution finding evolves and how it is communicated and (implicitly) coordinated in a group.

\section{Table 2. Characteristics of the main group types.}

\begin{tabular}{cccc}
\hline \multicolumn{4}{c}{ Group types } \\
\hline Clique & Concern & Factory & Team \\
\hline \multicolumn{4}{c}{ General actions are directed to } \\
\hline $\begin{array}{c}\text { The consent with the } \\
\text { general idea }\end{array}$ & The free initiative & The strong management & Detailed discussions \\
\hline
\end{tabular}


ISSN 2029-8587

PROBLEMS

OF PSYCHOLOGY

IN THE $21^{\text {st }}$ CENTURY

Vol. 9, No. 1, 2015

10

\section{Group types}

\begin{tabular}{|c|c|c|c|}
\hline \multicolumn{4}{|c|}{ Problems are solved on the basis of } \\
\hline $\begin{array}{l}\text { Preliminary agreement with } \\
\text { the tasks and goals }\end{array}$ & Individual creative activities & $\begin{array}{c}\text { Clear and concentrated } \\
\text { analysis }\end{array}$ & Open interaction \\
\hline & Leadership is based on & & Leadership is based on \\
\hline $\begin{array}{l}\text { Shared views on the } \\
\text { direction of common } \\
\text { movement }\end{array}$ & $\begin{array}{l}\text { Presence of authority and } \\
\text { acceptance }\end{array}$ & Power and status & $\begin{array}{l}\text { Co-interaction with relations } \\
\text { and collaboration }\end{array}$ \\
\hline \multicolumn{4}{|c|}{ Chronic problems are solved with the help of } \\
\hline $\begin{array}{l}\text { Ignoring the problems and } \\
\text { refusing their discussions }\end{array}$ & $\begin{array}{l}\text { The search for creative } \\
\text { approaches }\end{array}$ & $\begin{array}{l}\text { Strengthening the } \\
\text { administration and following } \\
\text { the rules }\end{array}$ & $\begin{array}{l}\text { A more tense discussion } \\
\text { and new ways of solving } \\
\text { the problem }\end{array}$ \\
\hline \multicolumn{4}{|c|}{ Daily work } \\
\hline $\begin{array}{l}\text { Is done with the least } \\
\text { intervention into it }\end{array}$ & $\begin{array}{l}\text { Is done and changed for } \\
\text { everybody in a different way }\end{array}$ & $\begin{array}{c}\text { Depends on the stability of } \\
\text { the course and the activity } \\
\text { of the authorities }\end{array}$ & $\begin{array}{l}\text { Is constantly checked for } \\
\text { further enhancement }\end{array}$ \\
\hline \multicolumn{4}{|c|}{ Roles and responsibilities } \\
\hline $\begin{array}{l}\text { Are realized with nearly } \\
\text { automatically accuracy }\end{array}$ & $\begin{array}{l}\text { Result in a way as people } \\
\text { do }\end{array}$ & $\begin{array}{l}\text { Are put down and made } \\
\text { firmer }\end{array}$ & $\begin{array}{l}\text { Are separated and replaced } \\
\text { if necessary }\end{array}$ \\
\hline \multicolumn{4}{|c|}{ Desires and interests of individuals are } \\
\hline $\begin{array}{l}\text { Evaluated according to the } \\
\text { degree of their coordination } \\
\text { with the goals of the } \\
\text { organization }\end{array}$ & $\begin{array}{c}\text { Considered more important } \\
\text { than the interests of the } \\
\text { organization }\end{array}$ & $\begin{array}{l}\text { Subject to the interests of } \\
\text { the organization }\end{array}$ & $\begin{array}{l}\text { Coordinated with the } \\
\text { interests of the organization } \\
\text { with the help of agreement }\end{array}$ \\
\hline \multicolumn{4}{|c|}{ Administration } \\
\hline $\begin{array}{l}\text { Assigns the context and } \\
\text { the goal minimizing the } \\
\text { intervention }\end{array}$ & $\begin{array}{l}\text { Gives people the } \\
\text { opportunity to act as they } \\
\text { consider it necessary }\end{array}$ & $\begin{array}{c}\text { Determines the leaders } \\
\text { and possible directions of } \\
\text { development }\end{array}$ & $\begin{array}{l}\text { Acts as a catalyst of group } \\
\text { interaction and cooperation }\end{array}$ \\
\hline \multicolumn{4}{|c|}{ Disagreements and conflicts } \\
\hline $\begin{array}{l}\text { Reflect the fact of } \\
\text { separation of overall goals } \\
\text { and tasks }\end{array}$ & $\begin{array}{c}\text { Are productive } \\
\text { manifestations of individual } \\
\text { characteristics and } \\
\text { differences }\end{array}$ & $\begin{array}{c}\text { Are threats to the stability of } \\
\text { the organization and impede } \\
\text { the work process }\end{array}$ & $\begin{array}{l}\text { Are vital for the effective } \\
\text { solution of the problem }\end{array}$ \\
\hline \multicolumn{4}{|c|}{ Communication is } \\
\hline Limited and unimportant & $\begin{array}{l}\text { Changed according } \\
\text { to intensity and is not } \\
\text { predictable }\end{array}$ & Formal and subject to rules & Is open and saturated \\
\hline \multicolumn{4}{|c|}{ Information and data (as a rule) are } \\
\hline $\begin{array}{l}\text { Evaluated as overall } \\
\text { knowledge which shouldn't } \\
\text { be shared }\end{array}$ & $\begin{array}{l}\text { Used for individual } \\
\text { achievement }\end{array}$ & $\begin{array}{c}\text { Controlled and an access to } \\
\text { them is limited }\end{array}$ & $\begin{array}{l}\text { Obviously evaluated and } \\
\text { distributed }\end{array}$ \\
\hline
\end{tabular}

Characteristics of a "Coordinator"

Mode of impact: beneficial exchange (you give me - I give you).

Specification of the method: economizing the benefits. Resources for exchanging the outcome are: money, status, advance in career, fame, free time, etc.

Form of communication: agreement-contract.

Form of stating the problem: in a form a problem (as a contradiction between what should be and what it is). The targets are linked to the employee's personal goals.

Perception of the employee: active person with his/her personal goals who is interested in beneficial game rules and tangible rewards.

Valuable qualities: independence, efficiency. 
Criteria of leader's efficiency: high level of efficiency of each employee ("stars"), instructor's ability to seek/find resources and negotiate.

\section{“Team” Working Group Type}

Recently a special type of joint activities, co-creative type, has been singled out (Malinowski, 1990). This type of organization of joint activity originated in the fields of science and art, where the participants of a scientific or creative project created something entirely new and often unique, which was impossible to create with available rules and technologies. Within such groups a special type of activity is created/established, co-creation, when each participant of the process is considered to be the equal creator of a novelty. The laws of creation process require recording of everyone's contribution, even the "craziest" one, as an opening may be created from the most absurd idea during overall discussions. This type is characterized by a specific activity of each of the participants in the process of interaction, especially the activity which improves one's professional competence through participation in joint activities. On the one hand, features of co-creative group activities allow each participant to try different ways of activity, enrichen means of working with that of other professionals and spheres of work. But on the other hand, the synergistic (enriching) effect gives a powerful impulse to the development of the group which performs the activity. Another feature of this type is that the "traces" of individual contributions of each participant aren't fundamentally distinguished.

The peculiarity of the participation of each employee in co-creative type of activity is the fact that the members of this team have the opportunity to work in completely different professional positions, and perform a variety of collective roles depending on the task the group is facing at that point. Therefore, these groups usually have a high flexibility and variability both of the staff and the internal structure depending on the objectives and the conditions for their fulfillment. As an example of this type of activity serves the work of creative teams, in which each participant is given the opportunity to manifest himself/herself. Nonetheless, the goal of the group, the creation of a new, culturally-valuable product, is achieved as a whole, (Human Resource Management, 2006).

"Team" working group type is a dynamic, entrepreneurial and creative work environment/ place. Here an emphasis is put on the development and acquisition of new capabilities. People here are willing to improvise and take risks. In such groups leaders are innovators who prefer experimenting. Success means continuous development to produce unique and new products and/ or services. The team encourages individual initiative and freedom.

Representatives of the participatory culture are characterized by a particular orientation on professional development. It differs from the ambitions of the participants of entrepreneurial culture. In this case, it is not so much about the deepening within the same problem or profession, but about working in border areas of human activity. A professional opposed to a specialist is even able to go beyond his/her specialty and work using the tools of other professionals, which allows him/her not only to find the novelty, but also to deepen his/her understanding of the problem. People of this team type are oriented to cooperation with specialists from different fields, to flexibility of changing attitudes and to individual development. The basic aim of such teams is to acquire new knowledge, to create conditions for personal development, and to have respect towards the rights of each work participant. Opposed to organizations with organic culture, here it is impossible to solve problems with the majority of voices and to introduce the dictatorship of the majority. Problems should be solved by the consensus and the final decision must necessarily give the possibility for the realization of the legitimate interests of minorities as their rights can never be violated. Team-member back and forth quality is proposed as a role-making invent complementary to leader-member back and forth quality. Research results from a sample of blue collar industrial workers show that team-member exchange rate adds to the prediction of job attitudes by leader-member exchange quality, and that team-member exchange quality differs orderly between groups in dealings to the autonomy given teams by management and within groups in relation to job attitudes. Team-member back and forth quality also forecast rated interpretation, subject to the moderating effects of peer boost. Implications for role-making theory and research as well as for the practice of team-based management, are discussed. According to Lahtero and 
OF PSYCHOLOGY IN THE $21^{\text {st }}$ CENTURY Vol. 9, No. 1, 2015

12

Kuusilehto-Awale (2013) there are several types of leadership. One of them is known as strategic planning and it is the first element of strategic leadership. It is essential, because of the predictability of the environments being hard due to quick change. Strategic planning combines systematic recapture and use of data to determine the direction for the long-lasting timeline. It is a mixture of cogitating the future, analyzing the aims and evaluating the precedence. It is about ensuring the feasibility and effectiveness of the organization with the means of mapping the direction for future action. Strategic planning also embraces the creation of the organizational mission, vision and strategies. Strategic planning is mainly useful only when it is connected in order to implement the strategy. Strategic leadership has to focus on the objectives defined in the strategy, and for the strategy to be operational, the work of the whole personnel has to be aligned with what is defined in the strategy. Working in line with the strategy implies how the staff are induced to commit themselves to the strategy and to put it into effect in their daily work. Strategic vision can only be achieved by the attachment and loyalty of the personnel to it. The level of attachment depends on how close and important the strategy implementation is perceived to be. If the strategy is not opened in discussions and brought close to the practice, its significance remains superficial and alien. This decreases the will to commit to the work. Comprehension and perceiving the entity are therefore essential for launching the strategy to the field. An employer can take responsibility for the development of their own strategic capacity only when they are conscious of the long-term strategic direction and vision.

\section{Characteristics of a "Superleader"}

Mode of impact/influence: envolvement.

Specification of the method: inspiration by the aim, a professional challenge, a free choice, a common fate, professional opportunities.

Form of communication: coherence of actions, common consent with the distribution of responsibilities.

Form of stating the problem: formulation of an ambitious and scaled goal with a professional challenge, the designation of its role in the development of an employee or of a company.

Perception of the employee: a person who is oriented in professional growth and is interested in the possibilities of development.

Valuable qualities: creativity, initiative, learning intentions.

Criteria for leader's efficiency: continuous development of workers, organization of a creative team, which is capable of dealing with a completely new challenges.

\section{Conclusions}

An intent with this analysis was to review the literature on organizational culture and team leadership and as a direction of training professional psychologists and tried to suggest a framework that integrates existing team leadership research and describes the full range of ways in which leadership can manifest itself within a team (Table 2). Though it should be noticed that "like any typological approach, singling out these styles may possess its opportunities and constraints. Thus, the major benefit of the typological approach is its quick and easy-to-use source of knowledge that generates a precise and eloquent result. However, the weak point of the

typology is skipping fine details typical of everybody's individuality. At the same time, the study of a personality's response to the changing environment has produced more new questions rather than gave exhaustive answers to the initial ones. In particular, we believe that future research should target the correlation of individual personal characteristics, styles of response to changes, and such parameters of the changing environment as readiness of personnel, availability of resources (Bazarov, 2007), scale of changes (Ross \& Nisbett, 1999), nature of changes, principles of corporate culture existing within the company." 


\section{References}

Bazarov, T. Yu. (2012). Social psychology of instability within organizational reality. Psychology in Russia: State of the Art, 5, 271-288. DOI: 10.11621/pir.2012.0016.

Bazarov, T. Yu., \& Shevchenko, Yu. S. ( 2013). The executive leader in the postcrisis era. Psychology in Russia: State of the Art, 6 (2), 4-19.

Bazarov, T. Yu., (n.d.). Psychological aspects of an organization undergoing changes. Moscow: AspektPress.

Cameron, K. S., \& Ettigton, D. R. (1988). The conceptual foundations of organizational culture. Higher education: Handbook of Theory and Research. New York: Agathon, p. 356-396.

Cameron, K. S., \& Quinn, R. E. (1999). Diagnosing and changing organizational culture: Based on the competing values framework. Addison Wesley Logman.

Ross, L., Nisbett, R. (1999). Man and situation: Lessons of social psychology. Moscow: Aspekt-Press.

Standards for Social Work Practice with Groups, Second Edition Association for the Advancement of Social Work with Groups (2013). Inc. Retrieved from http://www.aaswg.org/standards-social-workpractice-with-groups

Colonel Shaun A. Burley British Army (2005) XI. Contrasting styles of command: French and German approaches during the 1940 campaign. Defence Studies, 5 (1), 138-150. DOI: 10.1080/1470243050009.

Lahtero, T. J., \& Kuusilehto-Awale, L. (2013). Realisation of strategic leadership in leadership teams'work as experienced by the leadership team members of basic education schools. School Leadership \& Management: Formerly School Organisation, 33 (5), 457-472. DOI: 10.1080/13632434.2013.813464qw.

Badke-Schaub, P., Neumann, A., Lauche, K., \& Mohammed, S. (2007). Mental models in design teams: A valid approach to performance in design collaboration? CoDesign: International Journal of CoCreation in Design and the Arts, 3 (1), 5-20. DOI: 10.1080/15710880601170768.

Advised by Judita Stankute, SMC “Scientia Educologica”, Lithuania

Received: April 05, 2015

Accepted: June 25, 2015

Tahir Y. Bazarov

PhD., Professor, Chairman of the Expert Council RPS, Member of the Presidium

RPS, Lomonosov Moscow State University, Moscow, Russia.

E-mail: thbazarov@mail.ru

Vladimir S. Karapetyan

PhD., Professor, Armenian State Pedagogical University after Kh. Abovyan, 17

Tigran Mets Ave., Yerevan, 375010, Armenia.

E-mail: vskarapetyan@mail.ru

Website: http://www.armspu.am/home/ln/en

Srbui R. Gevorgyan

PhD., Professor, Armenian State Pedagogical University after Kh. Abovyan,

Armenia.

E-mail: gevorgyan_26@mail.ru 